\title{
PATIENT PROFILE WITH EARLY STAGE BREAST CANCER SUBMITTED TO INTRAOPERATIVE RADIOTHERAPY IN TERTIARY SERVICE IN GOIÂNIA
}

Lais T. Maya', Paola F. Freitas', Priscila D. Watanabe², Gustavo L. Q. Lima³, Luiz Fernando P. Oliveira², Alexandre Marchiori X. Jesus'1, Ruffo Freitas-Junior 1,2,3, Nilceana M. A. Freitas 1,3

${ }^{1}$ CORA - Centro Avançado de Diagnóstico da Mama, Hospital das Clínicas, Universidade Federal de Goiás - Goiânia (GO), Brazil. IInstituto de Mastologia e Oncologia - Goiânia (GO), Brazil.

${ }^{3}$ Associação de Combate ao Câncer em Goiás, Hospital Araújo Jorge, - Goiânia (GO), Brazil.

Objective: Several studies shown that the overall survival and local control is the same applying segmental resection plus radiotherapy than mastectomy, but the time spent in the radiotherapy is considerably long. So, the intraoperative radiotherapy (IORT) came to reduce the days of treatment, with the same benefit. Intrabeam ${ }^{\circledR}$ is a type of IORT, indicated for selected women diagnosed with breast cancer, but treating partial breast instead of whole breast, with the same outcomes of conventional radiotherapy. Evaluate the profile of patients with early stage breast cancer diagnosis submitted to IORT. Methodology: Ten postmenopausal women with breast tumors and clinically negative axillary lymph nodes were evaluated between 09/2018-01/2019. All patients were submitted to quadrantectomy, sentinel lymph node biopsy, and IORT with Intrabeam ${ }^{\circledast}$. It was evaluated the age, menopausal status, unifocal tumors, tumor size, histological subtype, hormonal receptors, profile of invasions, and association with CDIS. Results: The mean age of the patients was 64 years. The majority of the lesions presented T1 pathological staging, only one T2 $(2.2 \mathrm{~cm})$; all surgical margins were free. CDI was the most prevalent, comprising $70 \%$ of all cases, against only 3 cases of CDIS, and 1 had the entire tumor excised with mamotomy. All patients evaluated had positive hormonal receptor tumors. As for oncoprotein c-erbB-2, 2 patients were positive. Only 1 patient presented lymph node commitment with macrometastases. When evaluating histological grade, 4 lesions presented intermediate grade, 3 presented low grade, and 2 lesions presented high grade. There was no vascular invasion in any of the analyzed lesions. The dose was $20 \mathrm{~Gy}$ prescribed on the surface of applicator, that varied from 4-5 cm. Only one patient presented local infection and none evolved with radiodermatitis. The greatest benefit for these patients was that $50 \%$ of them lived in other cities and even in other states, far from radiotherapy services. Conclusion: For selected patients with early breast cancer, a single dose of radiotherapy delivered at the time of surgery by use of targeted IORT should be considered as an alternative to external beam radiotherapy delivered over several weeks. The criteria for selecting low-risk patients to be submitted to IORT in this study was considered equivalent to those established by the consensus of the ESTRO (European Society for Radiotherapy and Oncology) and ASTRO (American Society for Radiation Oncology). 